\title{
FUNCTIONAL DYSACUSIS: THE UTILIZATION OF EEG ACTIVITY IN THE DETERMINATION OF HEARING THRESHOLD LEVEL, A CASE REPORT
}

\author{
I. HAY, B.SC. (ING.) (STELL.), M.A. (WASHINGTON U.) \\ Head, Department of Speech Science, Logopedics \\ and Audiology, University of Pretoria, Pretoria
}

\section{SUMMARY}

A case of functional dysacusis was subjected to routine as well as electric response testing. Test results were unreliable and electrical cortical responses to stimuli delivered to the right ear were so poor that the results could not be utilized. A marked difference between the raw EEG tracings was observed when stimuli were switched between left to right ears. This fact was eventually used to determine the hearing threshold level of the right ear.

\section{OPSOMMING}

'n Geval van funksionele disakusie is onderwerp an roetine en elektriese respons-toetse. Die toetsresultate was onbetroubaar en elektriese kortikale response op stimuli aan die regteroor gelewer, was so swak dat die resultate nie gebruik kon word nie. 'n Duidelike verskil tussen onverwerkte EEG-opnames is waargeneem by die skakeling van stimuli na die linker-en regterore. Hierdie feit is uiteindelik gebruik om die gehoorpeil van die regteroor te bepaal.

The designing of objective methods for testing the hearing ability of individuals who are unable to respond and those that are unwilling to respond to auditory stimuli, have occupied the minds of many clinicians for many years. The results can be seen in any audiology clinic in the form of test methods as well as test equipment. These methods and the equipment are in almost daily use all over the world. Few, however, can be regarded as successful in providing the clinician with an accurate indication of the true threshold level. since most methods are designed to differentiate between an elevated heáring level and a level that is closer to the real threshold hearing level.

This short paper reports the testing of a case of functional dysacusis who persistently reported that he perceived no sounds when acoustic stimuli were presented to the right ear even at levels of $110 \mathrm{~dB}$ I.S.O.

\section{CASE HISTORY:}

A normal, healthy male aged 20 years. No history of ear infection, exposure to excessive noise or deafness in the family. Hearing acuity in both ears deteriorated suddenly towards the end of 1972 with no known cause. He was 
happy in his work at the military dog school and there seemed no reason why he could be regarded as a malingerer.

\section{AUDIOLOGICAL ASSESSMENT:}

In response to requests by the Military Hospital, audiological tests were performed by the Hearing Clinic, of the Department of Speech Pathology and Audiology of the University of Pretoria.

The following test results were obtained:

Pure tone audiometry:

Left: Inconsistent HTL of approximately 50 - $60 \mathrm{~dB}$ I.S.O.

Right: No response (even at $110 \mathrm{~dB}$ I.S.O.)

Békésy audiometry:

Left: Type V

Right: No response.

Intra-aural reflex threshold:

Left: $95 \mathrm{~dB}$ I.S.O. (Technically good)

Right: 105 dB I.S.O. (Technically poor since a severe beat persisted on the balance meter)

Speech audiometry:

Left: SRT 35dB I.S.O.

Right: No response.

Evoked Response Audiometry:

Since the subject reported that no sounds were perceived in the right ear (not even a shadow curve was obtained!) it was decided to refrain from performing further subjective tests. Also the results of the intra-aural reflex threshold test gave an indication of a functional problem.

As a last resort it was decided to perform an ERA test using the PAR equipment available at the Clinic, in a quiet room but not sound proofed.

Electrode placement:

Vertex, right mastoid and forehead. Beckman Wafer electrodes were used.

Equipment settings:

Sensitivity: $50 \mu \mathrm{V} /$ div.

Pulse duration: $200 \mathrm{~ms}$.

Pulse interval: $1 \mathrm{sec}$.

Responses summated: 60

Filter passband: $1-15 \mathrm{~Hz}$. 
Testing the left ear.

Positive cortical responses (N90, P160) were identified when 250, 1000 and $3000 \mathrm{~Hz}$ tones of $40 \mathrm{~dB} \mathrm{HL}$ were presented to the left ear. The raw EEG trace (see Fig. 1) gave a steady, relatively low voltage recording.

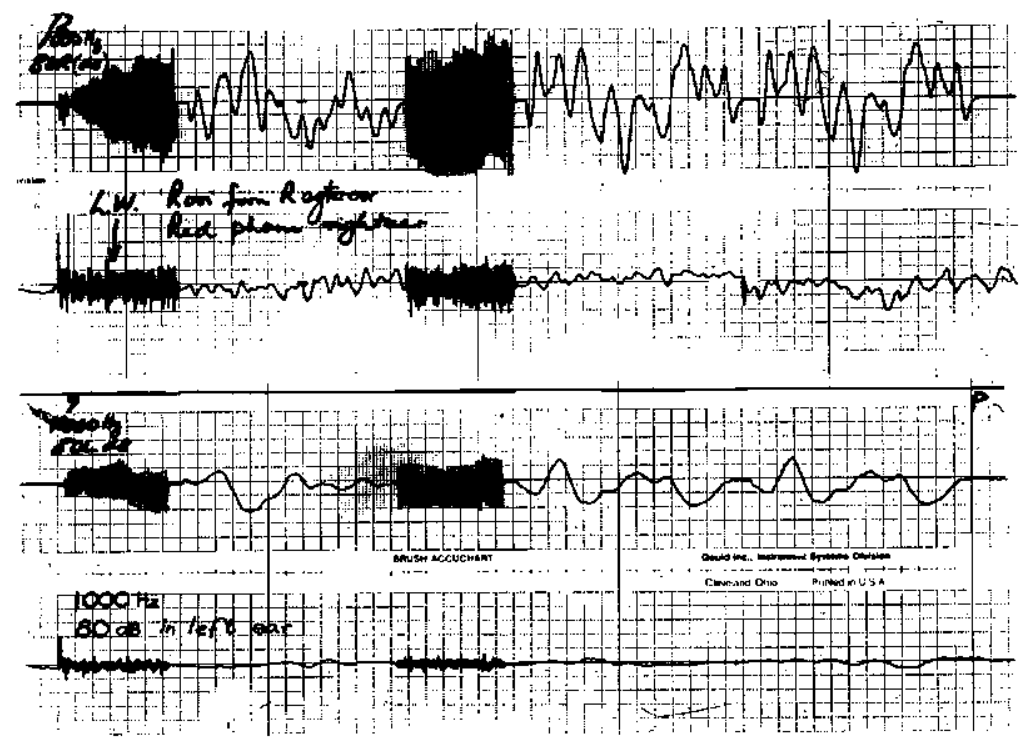

Figure 1. Summated evoked response and raw EEG tracings indicating the difference in the EEG tracings when auditory stimuli are perceived in the right and left ears. Sensitivity: $50 \mu \mathrm{V} /$ division.

Threshold estimation: OdB HL I.S.O.

Testing the right ear:

With the first presentation of high level tones to the right ear (from which no responses could be elicited up to this stage) it was noticed that the raw EEG trace changed drastically to a very high voltage trace. The background EEG was so unfavourable that no evoked response could be identified (see fig. 1).

Using the changing EEG tracings for threshold measurement:

When it became evident that the ERA method could not be used to determine the threshold of the right ear, it was decided to use the changing EEG by switching between left and right ears at different levels.

The results can be seen on Figs. 2, 3 and 4. In order to retain the same presentation method previously employed, responses were summated although the results could not be utilized. Only the changes in EEG were noted. 

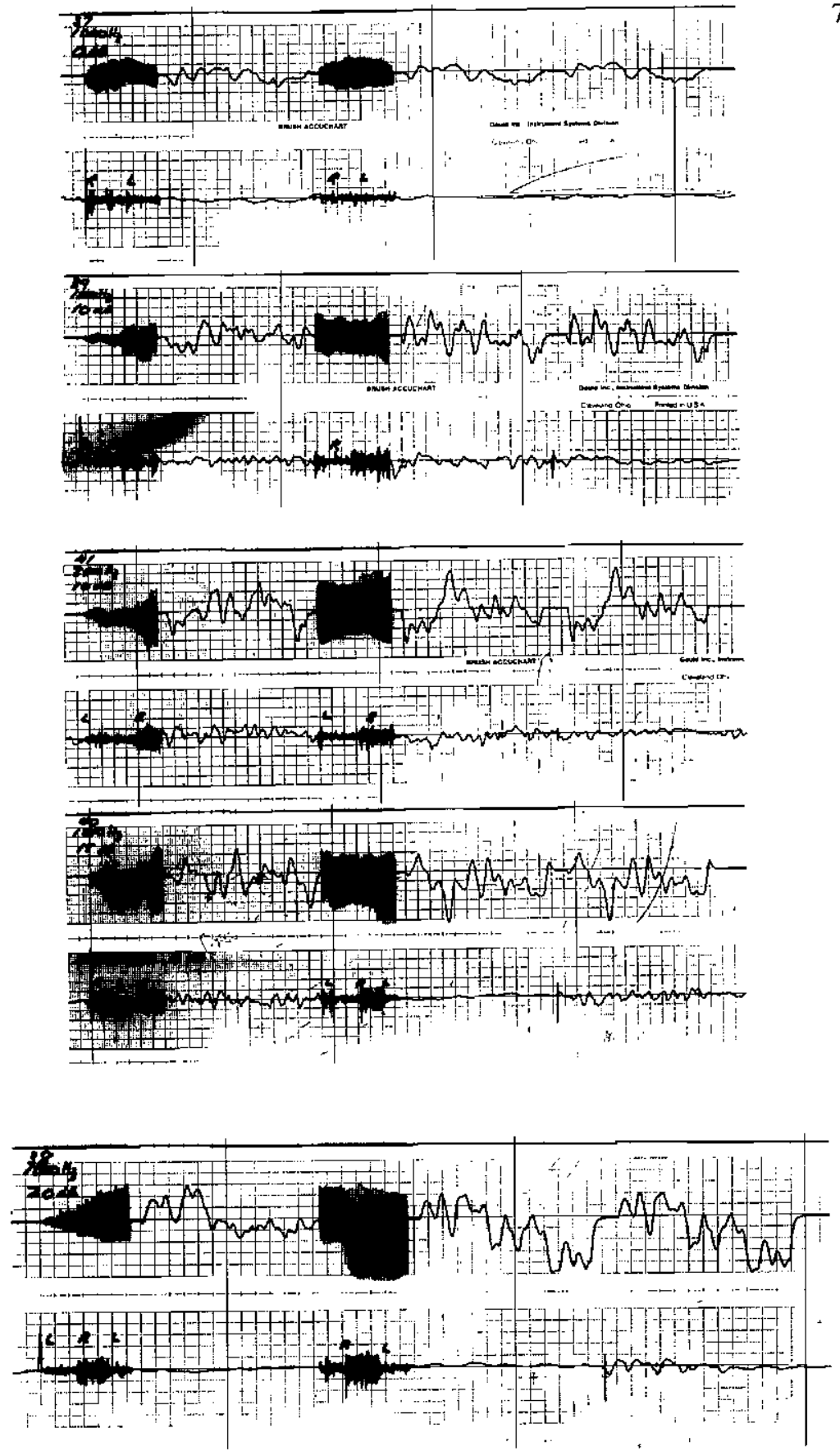

Figures 2, 3 and 4. Summated evoked responses and raw EEG tracings showing the effect that switching from left to right ear has on the EEG tracings. Sensitivity $50 \mu \mathrm{V} /$ division. 
To make absolutely sure that the EEG changes were not caused by the red earphone touching the electrode on the right mastoid, the phones were reversed. The reversal made no difference. Also, to make sure that the change in the EEG was related to actually hearing the stimuli, tests were performed at OdB HL in which case presentation of stimuli to left and right ears alternatively, made no difference to the EEG (see Fig. 2).

\section{RESULTS:}

Since the change in the EEG when presenting tones to the left and right ears alternatively, could be observed at 10dB HL I.S.O. at 1000 and $3000 \mathrm{~Hz}$ in a room that was not sound proofed, it was concluded that the patient had normal hearing in the right ear.

The markings $\mathrm{L}$ and $\mathrm{R}$ on the figures indicate the moments of switching to the Left and Right ears respectively. At low levels (Fig. 2) a delay was observed between the moment of switching to the right ear and the moment of EEG change. This was probably caused by an amount of uncertainty (at low levels) as to whether a sound was perceived or not.

\section{DISCUSSION:}

The case reported here might be an isolated one in that not all cases of functional dysacusis present this clear difference between EEG tracings when acoustic stimuli are switched between the left and right ears. It might be speculated that the increased EEG activity has an emotional basis which is understandable in the case of a malingerer who becomes aware of the fact that sounds are perceived in the ear which has the elevated threshold.

Subsequent tests performed two weeks later using only the changing EEG confirmed the results given above. At this time, however, the changes were identified at $15-20 \mathrm{~dB}$ HL I.S.O. The patient reported that the hearing to his right ear seemed to return to normal.

It might be advantageous to subject all malingerers and individuals with functional overlays to the EEG method of testing, to determine whether this phenomenon can be observed more often. 